\title{
En bloc pelvic resection for advanced ovarian cancer preceded by central ligation of vessels supplying the tumor bed: a description of surgical technique and a feasibility study
}

Jacek Jan Sznurkowski

\begin{abstract}
Background: The resection of all visible malignancies increases the likelihood for long-term survival in epithelial ovarian cancer. The complete extinguishment of pelvic disease is possible using en bloc pelvic resection. The no-touch isolation technique aims to reduce cancer cells flowing from the primary tumor site to the liver and other organs by ligating blood and lymphatic vessels first. objectives are to present the operative details and to establish the feasibility of the modified technique of en bloc pelvic resection, which begins with the central ligation of vessels supplying the tumor bed.

Methods: Twenty patients with pelvic tumor extensively infiltrating into adjacent pelvic organs were uniformly operated on. The surgical plan commenced with incisions along the lateral peritoneal reflections immediately medial to the white line of Toldt followed by a retroperitoneal central ligation of ovarian and mesenteric vessels and the ovarian lymphovascular flow. Then, the routine steps of en bloc pelvic resection were performed. Data on treatment were assessed.

Results: In all cases, no gross residual disease was achieved. The median durations of the surgical procedure and the hospital stay were $320 \mathrm{~min}$ (range: 205-430 min) and 12 days (range: 7-44 days), respectively. The complications were as follows: wound infection $(n=1)$, anastomosis dehiscence $(n=1)$, total parenteral nutrition $(n=4)$, and death $(n=1, \mathrm{PE})$. The median follow-up time period was 19 months (range: 8-31 months). No patient experienced a recurrence of pelvic disease.
\end{abstract}

Conclusions: Performing a central ligation of vessels supplying the tumor bed prior to an en bloc pelvic resection is feasible with acceptable morbidity and mortality rates.

Keywords: Ovarian cancer, En bloc pelvic resection, Complete pelvic peritonectomy, No-touch isolation, Surgery, Cytoreduction 


\section{Background}

Epithelial ovarian carcinoma (EOC) is the leading cause of death due to gynecologic malignancy, and more than $60 \%$ of women with newly diagnosed EOC present with advanced stage disease [1]. Current standard treatment for advanced ovarian cancer consists of a primary debulking surgery (PDS) followed by platinum-based chemotherapy $[2,3]$. Several studies support a greater survival rate in patients who were optimally cytoreduced compared with patients who were suboptimally cytoreduced [4-7].

The possibility of excising all visible lesions $(R=0$, microscopic) is crucial for deciding whether to perform an extensive cytoreductive surgery.

En bloc pelvic resection is effective for achieving maximal cytoreduction while eliminating the pelvic disease in advanced primary EOC patients with extensive pelvic organ involvement including viscera [8].

Lymphovascular ligation before tumor manipulation during cancer resection is termed the "no-touch isolation" technique [9]. This technique aims to reduce the intraoperative dissemination of cancer cells and was proposed by Barnes [10] to decrease the incidence of liver metastases by diminishing the intraoperative dissemination of colorectal cancer cells.

Animal studies have confirmed this reduction [5], and recent data in humans suggest a trend towards reduced tumor cell dissemination with the no-touch isolation method [11, 12]. The benefit of this method in terms of improved patient survival, however, remains unproven [9].

To achieve cytoreduction to microscopic residual disease in disseminated EOC cases with peritoneal and visceral metastases consistent with the requirements of cancer notouch isolation, a modification of the en bloc pelvic resection procedure was introduced.

This modification aims initially to reach the retroperitoneal space where the lymphatic and vascular systems supplying the cancer tissue are located. Next, a central vascular ligation is performed. Finally, the intraperitoneal cancer compartment (including the infiltrated portion of bowel) is surrounded from the outside (healthy tissues) by separating the involved peritoneum from the bladder and the pelvic wall and then resected in one block. A colorectal anastomosis is created.

This paper aims to present a new surgical approach for advanced EOC and to share the initial experience of applying this approach.

\section{Methods}

\section{Population}

From May 2013 to October 2014, a modified en bloc pelvic resection was performed on 20 patients with advanced EOC at the Department of Gynecologic Oncology, Oncology Center, in Red Cross Hospital in
Gdynia, Poland. The study was approved by the local Ethics Committee (NKBBN/263/2012).

Inclusion criteria are as follows: age younger than 80 years old, ASA performance status 0 to 2 [13], resectable disease evaluated by computed tomography (CT) scan and/or positron emission tomography (PET), no significant comorbidities, and provided informed written consent. Exclusion criteria are as follows: other malignant pathologies, an extra-abdominal metastasis, a complete intestinal obstruction, or active infections.

The treatment plan consisted of performing a central vascular ligation prior to an en block pelvic resection. This treatment was a component of primary surgery aiming to remove all visible disease using different types of peritonectomy with related resections defined by Sugarbaker (Table 1) [14]. Each patient was operated on by JJS, who designed the surgical plan. The observation period ended 1st October 2015.

\section{Surgical plan}

(1) Mobilization of the left and right colons The peritoneum is incised along the lateral peritoneal reflections immediately medial to the white line of Toldt from the left and right paracolic sulci cephalad to the splenic and hepatic flexures of the colon. The mesentery of the left and right colons is divided from its retroperitoneal attachments (Fig. 1a).

Both ureters and the plane over Gerota's fascia are identified to avoid compromising the kidneys.

(2) Dissection and central ligation of ovarian vessels The left and right ovarian vessels are dissected and ligated at the level of the left renal vein and the vena cava, respectively (Fig. 1b).

(3) Central lymphovascular ligation with retroperitoneal selective lymph node dissection (if necessary) The lymphovascular flow is ligated by several clips. Enlarged, suspicious lymph nodes are excised at the level of the left renal vein (LRV) down towards the

Table 1 The visceral resections and parietal peritonectomy procedures

\begin{tabular}{ll}
\hline Type of peritonectomy & Provided resections \\
\hline Pelvic peritonectomy & $\begin{array}{l}\text { Uterus, ovaries, and rectosigmoid } \\
\text { colon }\end{array}$ \\
$\begin{array}{l}\text { Left upper quadrant } \\
\text { peritonectomy }\end{array}$ & Greater omentectomy and spleen \\
$\begin{array}{l}\text { Right upper quadrant } \\
\text { peritonectomy }\end{array}$ & $\begin{array}{l}\text { Tumor on Glisson's capsule of } \\
\text { the liver }\end{array}$ \\
Anterior parietal & Old abdominal incisions, umbilicus, \\
peritonectomy & and epigastric fat pad \\
Omental bursectomy & Gallbladder and lesser omentum \\
\hline
\end{tabular}



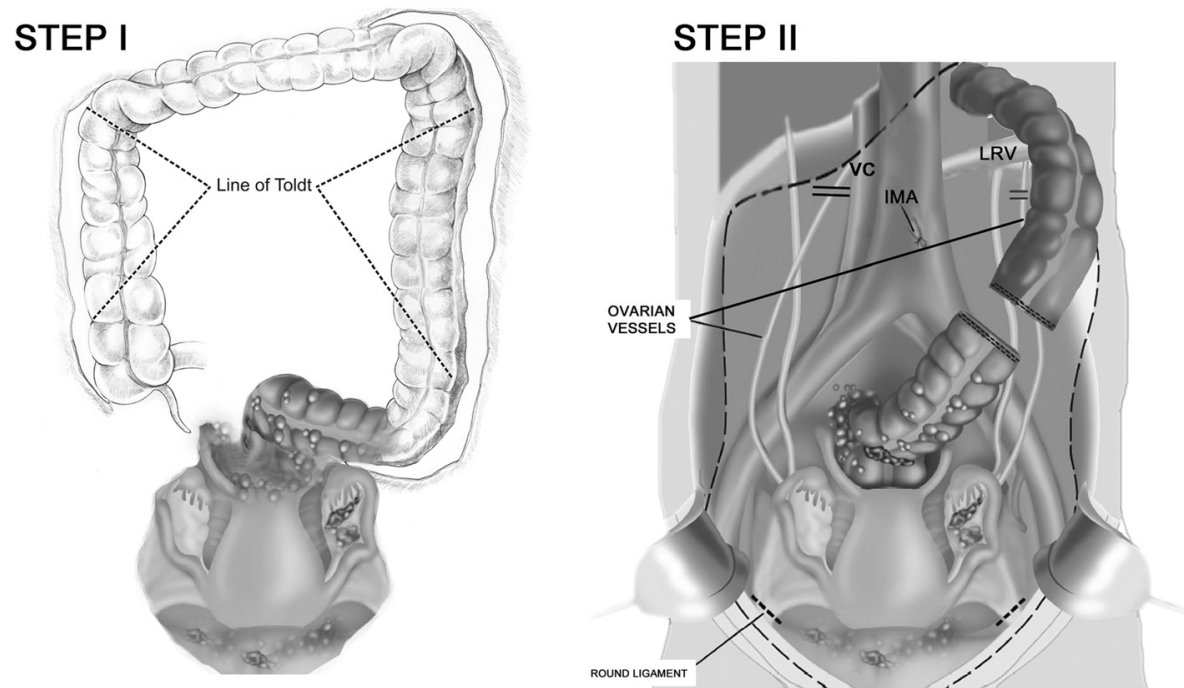

Fig. 1 The crucial steps of the proposed modification. a Entry into the extraperitoneal space and mobilization of the left and right colons. $\mathbf{b}$ Central vascular ligation of the tumor-bearing segment

pelvis in one block. Where possible, a nerve-sparing technique is used.

(4) Central vascular ligation of the tumor-bearing segment of the colon

The inferior mesenteric artery (IMA) is ligated on the aorta. The artery's individual branches are then resected as they arise from this vascular trunk (Fig. 1b). The Y-configuration of the left colic and sigmoidal vessels is converted to a $\mathrm{V}$-configuration to preserve the intermediate arcade. The inferior mesenteric vein (IMV) is divided as it courses around the duodenum.

(5) Division of the colon*

The colon is dissected $5 \mathrm{~cm}$ beyond the boundary of the cancer. A previous central vascular ligation and the mobilization of the left colon allowed for packing all the viscera, including the proximal colon, into the upper abdomen.

(6) Dissection of the mesorectum 2-3 cm below the retroperitoneal flexure

(7) Stripping of the vesical peritoneum with the underlying fatty tissues from the surface of the bladder

The point of tissue transection is precisely located between the bladder musculature and its adherent fatty tissue with peritoneum. The inferior limit of the dissection is the anterior wall of the vagina.

(8) Stripping of the parietal peritoneum The peritoneal incision around the pelvis is connected to the peritoneal incisions in the right and left paracolic sulci. The parietal pelvic peritoneum is transected from the muscles and fascia down towards the intraperitoneal space. The inferior limits of the dissection are marked by the boundaries formed by the broad ligament (the mesoovarium, the mesosalpinx, and the mesometrum), the mesorectum, and the mesocolon.

(9) Extraperitoneal cutting of the broad ligament The round ligaments are divided as they enter the internal inguinal ring.

(10) Central ligation of the uterine arteries Uterine arteries are ligated laterally to the ureter at their origin, the anterior division of the internal iliac artery (marginal ligation). This ligation enables the excision of the entire parametrium in one block with the main specimen.

(11) Dissection of the uterus at the level of the fornices of the vagina

The lower aspect of the uterus is dissected from the vagina, and the vaginal cuff is closed.

(12) Dissection of the rectum

The rectovaginal septum is exposed. The perirectal fat is divided $2-3 \mathrm{~cm}$ beneath the peritoneal reflection so that the portion of the tumor occupying the cul-de-sac is removed intact with the specimen. The rectal musculature is skeletonized using electrosurgery so that a stapler/purse-string can be used to close the rectal stump. Finally, the rectum is divided, and the cancer specimen is removed.

(13) Creation of a colorectal anastomosis The proximal colon is anastomosed to the rectal remnant with a stapling device.

End-to-end: A circular stapling device is passed into the rectum, and the trochar penetrates the staple line. A purse-string applier is used to secure the 
stapler anvil in the distal descending colon.

The body of the circular stapler and anvil are mated, and the stapler is activated to complete the low colorectal anastomosis.

Side-to-end: The purse-string clamp is applied at the inferior level of the resection. A straight needle is passed through the clamp to form purse-string sutures, which are used to secure the staple anvil in the rectal stump.

The lumen of the colon is visualized and progressively widened using three dilators of increasing diameters $(25,28$, and $31 \mathrm{~mm})$. The EEA instrument is inserted through the end of the colon, and the trochar penetrates the sidewall of the bowel. The body of the circular stapler and anvil are mated, and the stapler is activated. The circular stapler is then removed, and the distal end of the colon is closed below the colorectal anastomosis with a linear stapler TA 55.

(14) Leak testing

\section{Of colorectal anastomosis}

To evaluate the stapled colorectal anastomosis, the proximal and distal tissue rings are examined for completeness.

Air leak testing is conducted, and air is insufflated into the rectum with a water-filled pelvis to check for an airtight circle of staples. Two hands should easily pass beneath the sigmoid colon to ensure no tension at the stapled anastomosis. A rectal examination is conducted to check for staple-line bleeding at the anastomosis.

\section{Of the bladder}

The integrity of the bladder is analyzed with an intraoperative methylene-blue test (IMBT).

"The division of the colon is delayed, while a greater omentectomy is conducted first. This order of operations enables an assessment of the "oncological cleanliness" of the entire colon to select the optimal place for cutting. The splenic flexure and the transverse colon are frequently involved, which involvement is hidden by the metastatic omentum.

\section{Results}

The median age of patients was 58 years (range: 3680 years). The median body mass index (BMI) was 25.7 (range: 21-30). High-grade serous ovarian cancer (HGSOC) was the predominating histological type and was detected in 15 of 20 (75\%) cases. The most common FIGO stage was IIIC confirmed in $50 \%$ of patients. Most cases presented with ascites exceeding $1000 \mathrm{ml}$ (80\%). Detailed data of the pre-treatment and disease-related characteristics are shown in Table 2.

In all cases, no gross residual disease was achieved. In all cases, histopathology results also confirmed bowel
Table 2 Patients characteristics

\begin{tabular}{ll}
\hline Feature & Value/no. of patients \\
\hline Median age years & 58 years (range 36-80) \\
Median BMI & 25.7 (range 21-30) \\
ASA score $^{\text {a }}$ & \\
1 & 6 \\
2 & 11 \\
3 & 3 \\
Tumor histology & \\
HGSOC & 15 \\
LGSOC & 1 \\
Endometroid & 2 \\
Clear cell & 1 \\
Musinous & 1 \\
FIGO stage & \\
II B & 2 \\
III B & 3 \\
III C & 10 \\
IV A & 5 \\
Ascites & \\
$<1000 \mathrm{~cm}^{3}$ & \\
$>1000 \mathrm{~cm}^{3}$ & \\
\hline
\end{tabular}

${ }^{a}$ American Society of Anesthesiologists Classification of Physical Status

${ }^{\mathrm{b}}$ International Federation of Gynecology and Obstetrics

infiltration of the cancer cells with the involvement of mesenteric lymph nodes in 11 cases (55\%). Operative details are shown in Table 3. Samples of the removed tumor bed and the oncological clearness of the pelvis after surgery are shown in Fig. 2. The median duration of the procedure and hospital stay was 320 min (range: 205-430 min) and 12 days (range: 7-44 days), respectively. The median estimated blood loss (EBL) was $600 \mathrm{~cm}^{3}$ (range: 400-1000 $\mathrm{cm}^{3}$ ). Nineteen patients received blood transfusions (99\%). The median number of red blood cell (RBC) transfusion units was 4 (range: 0 to 6 units). Six of 20 patients $(30 \%)$ required postoperative intensive care. The median number of days spent by these patients in the intensive care unit (ICU) was 4 (range: 1-6 days). Four patients received total parenteral nutrition (20\%).

One patient experienced a complication associated with en bloc resection, namely an anastomosis site leak. This patient accordingly underwent further surgery during the same admission. The anastomosis site leak was managed with a diversion colostomy and pelvic cavity drainage. The colostomy was reversed after chemotherapy was complete. There were no surgery-related deaths; however, one woman died 12 days post-surgery. Her death was due to pulmonary embolismus, though all 20 patients received combined pharmacologic and mechanical methods of 
Table 3 The visceral resections and parietal peritonectomy procedures conducted during primary debulking surgery (PDS)

\begin{tabular}{|c|c|c|}
\hline Type of peritonectomy & Provided resections & $\begin{array}{l}\text { No. } \\
\text { of patients }\end{array}$ \\
\hline Pelvic peritonectomy & $\begin{array}{l}\text { Uterus, ovaries, and } \\
\text { rectosigmoid colon }\end{array}$ & 20 \\
\hline \multirow{3}{*}{$\begin{array}{l}\text { Left upper quadrant } \\
\text { peritonectomy }\end{array}$} & Greater omentectomy & 20 \\
\hline & Splenectomy & 4 \\
\hline & $\begin{array}{l}\text { Diaphragm: } \\
\text { stripping/resection }\end{array}$ & 1 \\
\hline \multirow[t]{2}{*}{$\begin{array}{l}\text { Right upper quadrant } \\
\text { peritonectomy }\end{array}$} & $\begin{array}{l}\text { Tumor on Glisson's } \\
\text { capsule of the liver }\end{array}$ & 1 \\
\hline & $\begin{array}{l}\text { Diaphragm: } \\
\text { stripping/resection }\end{array}$ & 4 \\
\hline \multirow[t]{2}{*}{$\begin{array}{l}\text { Anterior parietal } \\
\text { peritonectomy }\end{array}$} & $\begin{array}{l}\text { Old abdominal incisions, } \\
\text { umbilicus }\end{array}$ & 0 \\
\hline & epigastric fat pad & 0 \\
\hline Omental bursectomy & $\begin{array}{l}\text { Gallbladder and lesser } \\
\text { omentum }\end{array}$ & 0 \\
\hline \multirow[t]{2}{*}{ Type of lymhadenectomy } & Selective PALND/PLND & 10 \\
\hline & Systematic PALND/PLND & 2 \\
\hline
\end{tabular}

prophylaxis of venous thromboembolism (VTE) during hospital stay.

All surviving patients $(n=19)$ received platinum-based chemotherapy. The median number of days between the primary surgery and the first cycle of chemotherapy was 48 days (range: 20-147 days). The median follow-up time period was 19 months (range: 8-31 months). No patient experienced a recurrence of disease during the time of observation. Detailed data on the course of treatment for particular cases are shown in Table 4.

\section{Discussion}

The conventional technique procedure prioritizes the mobilization of the tumor-bearing segment followed by central vascular ligation and the ligation of other portions of the vasculature. Conversely, the no-touch isolation technique prioritizes central vascular ligation, followed by the mobilization of the tumor-bearing segment [9].

In advanced EOC, multi-visceral and peritoneal metastases create a tumor-bearing segment supplied by the extraperitoneal vascular system.

It is well-known that a complete peritonectomy and visceral resections are required to achieve a complete clearance of pan pelvic disease in these patients. The preponderance of data suggests that colon resection to achieve optimal cytoreduction positively impacts survival rates [15].

To achieve cytoreduction of microscopic residual disease in disseminated EOC cases consistent with the requirements of cancer no-touch isolation, a modified en bloc pelvic resection was proposed. This modified resection aims to initially reach the retroperitoneal space where the central vascular ligation is performed.

In the first step of the operation, the peritoneum is incised along the lateral peritoneal reflections immediately medial to the white line of Toldt from the left and right paracolic sulci cephalad to the splenic and hepatic flexures of the colon. The mesentery of the left and right colons is divided from all its retroperitoneal attachments. This dividing not only enables the identification of the ovarian and mesentery vessels but also elevates the entire colon with metastatic omentum, thus allowing the affliction of the upper abdomen with cancer to be properly assessed.

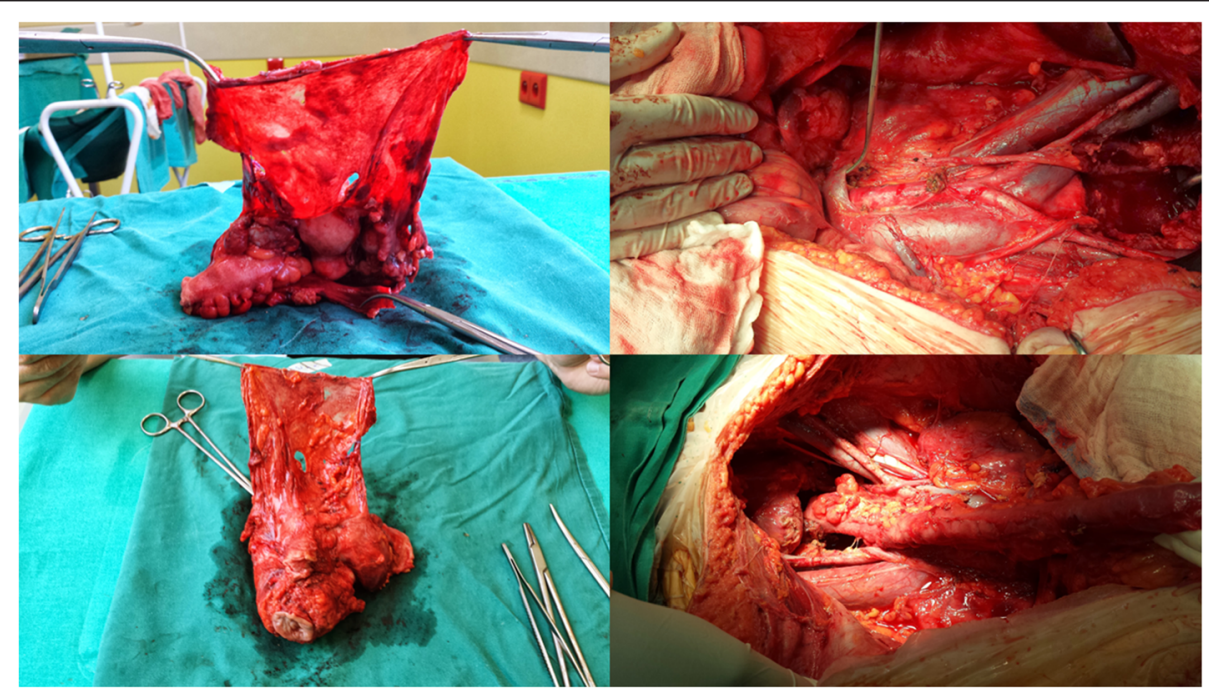

Fig. 2 Intraperitoneal cancer compartment (including the infiltrated part of the bowel) and oncological clearness following the modified en block pelvic resection 
Table 4 Modified en block pelvic resection-course of treatment

\begin{tabular}{|c|c|c|c|c|c|c|c|c|}
\hline Age years & Surgery duration minutes & $\mathrm{EBL} C \mathrm{C}$ & ICU days & RBC units & PN & Surgical complication & Hospital stay days & Time between PDS and Cht days \\
\hline 62 & 205 & 400 & 0 & 2 & 0 & 0 & 7 & 32 \\
\hline 58 & 310 & 600 & 0 & 4 & 0 & 0 & 13 & 31 \\
\hline 38 & 350 & 900 & 3 & 5 & 0 & 0 & 9 & 44 \\
\hline 62 & 350 & 400 & 0 & 4 & & Anastomosis leak & 25 & 48 \\
\hline 36 & 280 & 700 & 0 & 4 & 0 & 0 & 7 & 51 \\
\hline 74 & 210 & 400 & 0 & 0 & 0 & 0 & 12 & 62 \\
\hline 80 & 270 & 1000 & 5 & 6 & 1 & 0 & 12 & $x$ death \\
\hline 65 & 380 & 650 & 5 & 4 & 1 & Wound infection & 44 & 147 \\
\hline 64 & 345 & 400 & 5 & 1 & 1 & 0 & 12 & 52 \\
\hline 64 & 310 & 600 & 0 & 4 & 1 & 0 & 18 & 48 \\
\hline 52 & 305 & 450 & 0 & 1 & 0 & 0 & 13 & 48 \\
\hline 55 & 410 & 400 & 0 & 2 & 0 & 0 & 9 & 35 \\
\hline 66 & 320 & 550 & 0 & 3 & 0 & 0 & 15 & 61 \\
\hline 54 & 300 & 700 & 0 & 5 & 0 & 0 & 11 & 53 \\
\hline 55 & 430 & 950 & 1 & 5 & 0 & 0 & 12 & 26 \\
\hline 72 & 320 & 400 & 0 & 2 & 0 & 0 & 12 & 31 \\
\hline 48 & 345 & 600 & 0 & 4 & 0 & 0 & 9 & 56 \\
\hline 59 & 300 & 800 & 0 & 6 & 0 & 0 & 12 & 60 \\
\hline 46 & 355 & 500 & 0 & 3 & 0 & 0 & 8 & 20 \\
\hline 54 & 345 & 700 & 1 & 4 & 0 & 0 & 20 & 25 \\
\hline
\end{tabular}

$E B L$ estimated blood loss, ICU intensive care unit, $R B C$ red blood cell, $P N$ parenteral nutrition, PDS primary debulking surgery, Cht chemiotherapy

It has been suggested that the inefficiency of upper abdomen surgery limits optimal cytoreduction [16]. Hence, this surgical step could reveal all potentially unresectable lesions and is therefore proposed to initiate all aggressive surgical plans to eradicate EOC.

The left and right ovarian vessels are dissected and ligated at the level of the left renal vein and the vena cava, respectively.

Central vascular ligation of the tumor-bearing segment of the colon is performed. From a practical perspective, this ligation should be proceeded by the opening of the omental bursa to assess the "oncological cleanliness" of the colon.

The surgical plan includes central lymphovascular ligation and retroperitoneal lymph node dissection (LND). LND is a questionable procedure to use in cases of advanced ovarian cancer. We aimed to excise enlarged, suspicious nodes during the cytoreduction or to perform a systematic lymphadenectomy in cases with cancer spread macroscopically limited only to the pelvis. Current prospective studies such as the LION study (AGO-Ovar) will confirm the appropriateness of using LND in EOC. Notably, none of the 12 cases showed postoperative lymphocele with the lymph node dissection, which result could indicate another positive impact of performing the central lymphovascular ligation prior to excising enlarged, suspicious nodes.
The next proposed modification entails an excision of the entire segment of affected peritoneum, including areas without visible lesions. For example, if the peritoneal metastases are present in the pelvis, a complete pelvic peritonectomy is conducted. Recently, radical surgery together with hyperthermic intraperitoneal chemotherapy (HIPEC) as described by Sugarbaker [14] has been widely promoted for use in EOC cases.

Sugarbaker did not excise uninvolved surfaces of the peritoneum because he believed that microscopic disease, if unaddressed, will be eradicated by HIPEC performed immediately after surgery. Existing evidence suggests that primary debulking surgery followed by HIPEC has an unexpectedly negative impact on prognosis in EOC [17]. The results of ongoing randomized control trials will be published not sooner than in the next 3 years. Therefore, the approach of excising the entire segment of involved peritoneum, rather than performing experimental perioperative intraperitoneal chemotherapy, seems reasonable, particularly given the lack of observed complications related to the excision in our cohort.

\section{Rationale for modification}

The impact of no tough isolation technique on intraoperative cancer dissemination will be difficult to prove. However, the proposed central vascular ligation should, if not decrease intraoperative cancer dissemination, at 
least decrease complications such as blood loss and lymphocoele formation. Elevating the entire colon while opening the retroperitoneal space seems to be highly reliable for predicting optimal cytoreduction. Excising the entire segment of involved peritoneum, including areas without visible lesions, is safe and could be a cost-effective alternative for HIPEC.

\section{Course of treatment}

The duration of surgery and hospitalization was comparable to the respective durations reported in other studies on en block pelvic resection published after 2000 [18-24]. Patients in our cohort had a lower EBL and the highest rate of complete cytoreduction compared with other reports [18-24]. We believe that the decrease in blood loss is caused by the introduction of central vascular ligation and by the fact that surgery is starting from the healthy tissues surrounding the tumor compartment. It was proven that the tumor-bearing segment has increased vascularization caused by cancer neoangiogenesis [25]. A surgical operation conducted through an anatomically unchanged (i.e., healthy) compartment could also be responsible for the increased resectability of ovarian cancer tissue.

We observed anastomosis leakage in 1 of 20 cases (5\%). Only in one recent study was the percentage of this complication is higher (8.7\%) [23]. Remaining studies published after 2000 show lower rates of anastomosis leakage, namely $0.8 \%$, [19] $1.7 \%$ [21], $2.2 \%$ [22], $3 \%$ [24], $3.2 \%$ [20], and $4.5 \%$ [18]. All studies on en block pelvic resection were conducted with a limited number of cases, and the subsequent results of the studies do not reflect the real (average) rate of the anastomosis leakage of colorectal anastomosis. A meta-analysis of randomized control trials (RCTs) of colorectal anastomosis surgery published in 2001 revealed that the overall stapled clinical leak rate is $6.3 \%$ [26]. Given these data, our results (5\%) seem fully acceptable.

The single complication observed in our study could be explained by the poor nutritional status of the patient. We routinely analyzed serum albumin levels prior to surgery, yet this method appeared to be ineffective in identifying patients with severe nutritional risk. Since our study, we have incorporated an assessment of nutritional status based on the European Society of Parenteral Nutrition (ESPEN) Guidelines on Enteral Nutrition [27] into our qualification process. Currently, all patients with severe nutritional risk receive parenteral nutrition for 10-14 days prior to surgery even if surgery must be consequently delayed.

Recent studies on stapled colorectal anastomosis have indicated side-to-end anastomosis as safer than end-to-end anastomosis [28]. Side-to-end anastomosis tends to fill the pelvis, reducing the area of dead space in which a hematoma or collection of hematomas could develop [29].

Indeed, our observed case of leakage was one of two cases in which end-to-end colorectal anastomosis was created, which could thus be additional reason for the complication.

There were no surgery-related deaths; however, one woman died due to pulmonary embolismus 12 days post-surgery. She received combined pharmacologic and mechanical methods of prophylaxis of VTE during her hospital stay. Post mortem, it was found that she had been a mutation carrier of factor $\mathrm{V}$ Leiden. This fact was unpredictable; thus, we believe that her death should not affect the appraisal of the described surgical procedure.

All surviving patients received six courses of platinumbased chemotherapy.

The time interval from surgery to the start of chemotherapy was 48 days (range: $20-147$ days). This interval is longer than the average period of 4-5 weeks reported in the literature [30]. This delay has been suggested as impairing a patient's prognosis [31]. Recently, however, it was demonstrated that the timing of postoperative chemotherapy did not influence the overall survival rate in women without postoperative residual disease [30]. Indeed, none of our optimally debulked patients experienced a recurrence of the disease during the time of our observation. The median follow-up occurred only 19 months following surgery (range: 8-31 months). PFS periods reported in the literature range from 14 to 18 months [32]; hence, we believe that an en bloc pelvic resection preceded by a central ligation of the vessels supplying the tumor bed could potentially improve the outcome of ovarian cancer patients.

Prospective clinical trials with a control group are needed to assess the exact oncological benefit of the presented approach.

\section{Summary of proposed modification}

The tumor-bearing segment (pelvis) is not touched. In the first step, a retroperitoneal space is opened by incising along the lateral peritoneal reflections immediately medial to the white line of Toldt from the left and right paracolic sulci cephalad to the splenic and hepatic flexures of the colon. This method enables the vessels supplying tumor bed to be reached and ligated first (ovarian and mesenteric anterior vessels) as well as the lymph nodes involvement to be assessed. In advanced cases (including omental cake), this step should be proceeded by opening the omental bursa to assess the "oncological cleanliness" of the colon. Mobilization of the entire colon allows a proper determination of the affliction of the upper abdomen by cancer. Finally, intraperitoneal cancer compartment (including the infiltrated portion of the bowel) is surrounded from the outside (healthy tissues) by separating the entire 
peritoneum (not merely the involved portion) from the bladder and the pelvic wall and then resecting in one block. A colorectal anastomosis is created. In our cohort of 20 ovarian cancer patients, this new approach resulted in low blood loss and a high rate of optimal cytoreduction.

\section{Conclusions}

Performing a central ligation of vessels supplying the tumor bed prior to an en bloc pelvic resection is feasible with acceptable morbidity and mortality rates. The impact of this modification on intraoperative cancer spread and the decrease in blood loss as well as oncological outcome should be confirmed in future studies.

\section{Competing interests}

The author declares no competing interests.

\section{Author's contributions}

JJS conceptualized and designed the study; acquired, analyzed, and interpreted the data; and contributed to the statistical analysis, manuscript preparation, manuscript editing, and manuscript review.

\section{Acknowledgements}

Dudziak Mirosław - Head of the Department of Gynecologic Oncology, Oncology Center in Red Cross Hospital in Gdynia, Poland, who supported this trial and assisted in most of the performed operations.

Received: 5 January 2016 Accepted: 21 April 2016

Published online: 29 April 2016

\section{References}

1. Siegel R, Naishadham D, Jemal A. Cancer statistics, 2013. CA Cancer J Clin. 2013:63:11-30

2. Hoskins WJ, Bundy BN, Thigpen JT, Omura GA. The influence of cytoreductive surgery on recurrence-free interval and survival in smallvolume stage III epithelial ovarian cancer: a Gynecologic Oncology Group study. Gynecol Oncol. 1992;47:159-66.

3. Ozols RF, Bundy BN, Greer BE, Fowler JM, Clarke-Pearson D, Burger RA, et al. Phase III trial of carboplatin and paclitaxel compared with cisplatin and paclitaxel in patients with optimally resected stage III ovarian cancer: a Gynecologic Oncology Group study. J Clin Oncol. 2003;21:3194-200.

4. Chi DS, Liao JB, Leon LF, Venkatraman ES, Hensley ML, Bhaskaran D, et al. Identification of prognostic factors in advanced epithelial ovarian carcinoma. Gynecol Oncol. 2001;82:532-7.

5. Winter III WE, Maxwell GL, Tian C, Carlson JW, Ozols RF, Rose PG, et al. Prognostic factors for stage III epithelial ovarian cancer: a Gynecologic Oncology Group study. J Clin Oncol. 2007;25:3621-7.

6. Chi DS, Eisenhauer EL, Lang J, Huh J, Haddad L, Abu-Rustum NR, et al. What is the optimal goal of primary cytoreductive surgery for bulky stage IIIC epithelial ovarian carcinoma (EOC)? Gynecol Oncol. 2006;103:559-64.

7. Bristow RE, Tomacruz RS, Armstrong DK, Trimble EL, Montz FJ. Survival effect of maximal cytoreductive surgery for advanced ovarian carcinoma during the platinum era: a meta-analysis. J Clin Oncol. 2002;20:1248-59.

8. Chang SJ, Bristow RE. Surgical technique of en bloc pelvic resection for advanced ovarian cancer. J Gynecol Oncol. 2015;26:155. doi:10.3802/jgo.2015.26.2.155.

9. Atkin G, Chopada A, Mitchell I. Colorectal cancer metastasis: in the surgeon's hands? Int Semin Surg Oncol. 2005;2:5.

10. Barnes JP. Physiologic resection of the right colon. Surg Gynecol Obstet. 1952;94:723-6

11. Gall TM, Jacob J, Frampton AE, Krell J, Kyriakides C, Castellano L, Stebbing J, Jiao LR. Reduced dissemination of circulating tumor cells with no-touch isolation surgical technique in patients with pancreatic cancer. JAMA Surg 2014;149(5):482-5

12. Takii Y, Shimada Y, Moriya Y, Nakamura K, Katayama H, Kimura A, et al. A randomized controlled trial of the conventional technique versus the notouch isolation technique for primary tumor resection in patients with colorectal cancer: Japan Clinical Oncology Group Study JCOG1006. Jpn J Clin Oncol. 2014:44(1):97-100

13. Young J, Badgery-Parker T, Dobbins T, Jorgensen M, Gibbs P, Faragher I, Jones I, Currow D. Comparison of ECOG/WHO performance status and ASA score as a measure of functional status. J Pain Symptom Manage. 2015;49(2):258-64.

14. Sugarbaker $\mathrm{PH}$. An overview of peritonectomy, visceral resections, and perioperative chemotherapy for peritoneal surface malignancy. In: Sugarbaker PH, editor. Cytoreductive surgery \& perioperative chemotherapy for peritoneal surface malignancy. Textbook and video atlas. Woodbury: Cine-Med Publishers; 2012

15. Hoffman MS, Zervose E. Colon resection for ovarian cancer: intraoperative decisions. Gynecol Oncol. 2008;111(2 Suppl):S56-65.

16. Raspagliesi F, Ditto A, Martinelli F, Haeusler E, Lorusso D. Advanced ovarian cancer: omental bursa, lesser omentum, celiac, portal and triad nodes spread as cause of inaccurate evaluation of residual tumor. Gynecol Oncol. 2013:129:92-6.

17. Chiva LM, Gonzalez-Martin A. A critical appraisal of hyperthermic intraperitoneal chemotherapy (HIPEC) in the treatment of advanced and recurrent ovarian cancer. Gynecol Oncol. 2015;136(1):130-5.

18. Yildirim Y, Ertas IE, Nayki U, Ulug P, Nayki C, Yilmaz I, et al. En-bloc pelvic resection with concomitant rectosigmoid colectomy and immediate anastomosis as part of primary cytoreductive surgery for patients with advanced ovarian cancer. Eur J Gynaecol Oncol. 2014:35(4):400-7.

19. Clayton RD, Obermair A, Hammond IG, Leung YC, McCartney AJ. The Western Australian experience of the use of en bloc resection of ovarian cancer with concomitant rectosigmoid colectomy. Gynecol Oncol. 2002; 84(1):53-7.

20. Bristow RE, del Carmen MG, Kaufman HS, Montz FJ. Radical oophorectomy with primary stapled colorectal anastomosis for resection of locally advanced epithelial ovarian cancer. J Am Coll Surg. 2003;197(4):565-74.

21. Mourton SM, Temple LK, Abu-Rustum NR, Gemignani ML, Sonoda Y Bochner $\mathrm{BH}$, et al. Morbidity of rectosigmoid resection and primary anastomosis in patients undergoing primary cytoreductive surgery for advanced epithelial ovarian cancer. Gynecol Oncol. 2005:99(3):608-14.

22. Park JY, Seo SS, Kang S, Lee KB, Lim SY, Choi HS, et al. The benefits of low anterior en bloc resection as part of cytoreductive surgery for advanced primary and recurrent epithelial ovarian cancer patients outweigh morbidity concerns. Gynecol Oncol. 2006:103(3):977-84.

23. Richardson DL, Mariani A, Cliby WA. Risk factors for anastomotic leak after recto-sigmoid resection for ovarian cancer. Gynecol Oncol. 2006;103(2):667-72.

24. Peiretti M, Bristow RE, Zapardiel I, Gerardi M, Zanagnolo V, Biffi R, et al. Rectosigmoid resection at the time of primary cytoreduction for advanced ovarian cancer. A multi-center analysis of surgical and oncological outcomes. Gynecol Oncol. 2012;126(2):220-3.

25. Nishida N, Yano H, Nishida T, Kamura T, Kojiro M. Angiogenesis in cancer. Vasc Health Risk Manag. 2006;2(3):213-9.

26. Matos D, Atallah ÁN, Castro AA, Silva Lustosa SA. Stapled versus handsewn methods for colorectal anastomosis surgery. Cochrane Database Syst Rev. 2001;Issue 3. Art. No.: CD003144. doi:10.1002/14651858.CD003144.

27. Weimann A, Braga M, Harsanyi L, Laviano A, Ljungqvist O, Soeters $P$, et al. ESPEN Guidelines on Enteral Nutrition: surgery including organ transplantation. Clin Nutr. 2006;25(2):224-44.

28. Goulder F. Bowel anastomoses: the theory, the practice and the evidence base. World J Gastrointest Surg. 2012;4(9):208-13.

29. Taflampas P, Christodoulakis M, Tsiftsis DD. Anastomotic leakage after low anterior resection for rectal cancer: facts, obscurity, and fiction. Surg Today. 2009;39:183-8.

30. Hofstetter G, Concin N, Braicu I, Chekerov R, Sehouli J, Cadron I, et al. The time interval from surgery to start of chemotherapy significantly impacts prognosis in patients with advanced serous ovarian carcinoma—analysis of patient data in the prospective OVCAD study. Gynecol Oncol. 2013;131(1):15-20.

31. Mahner S, Eulenburg C, Staehle A, Wegscheider K, Reuss A, Pujade-Lauraine E, et al. Prognostic impact of the time interval between surgery and chemotherapy in advanced ovarian cancer: analysis of prospective randomized phase III trials. Eur J Cancer. 2013;49(1):142-9. doi:10.1016/j.ejca.2012.07.023.

32. du Bois A, Reuss A, Pujade-Lauraine E, Harter P, Ray-Coquard I, Pfisterer J. Role of surgical outcome as prognostic factor in advanced epithelial ovarian cancer: a combined exploratory analysis of 3 prospectively randomized phase 3 multicenter trials: by the Arbeitsgemeinschaft Gynaekologische Onkologie Studiengruppe Ovarialkarzinom (AGO-OVAR) and the Groupe d'Investigateurs Nationaux Pour les Etudes des Cancers de I'Ovaire (GINECO). Cancer. 2009;115:1234-44. 